\title{
Electric Field Grading Material Based on Thermally Reduced Graphene Oxide
}

\author{
W. Li, U.W. Gedde, H. Hillborg ${ }^{1}$ \\ Fiber and Polymer Technology, Royal Institute of Technology, SE- 10044 Stockholm, Sweden \\ ${ }^{1} A B B$ AB, Power Technology, Corporate Research, SE-721 78, Västerås, Sweden
}

\begin{abstract}
Silicone rubber filled with low amounts of thermally reduced graphene oxide exhibit non-linear conductivity with exposed to increased electric fields. Such material can be interesting as electric field grading material in HVDC cable accessories. In this study graphene oxide was thermally reduced (rGO) at 120 and $180{ }^{\circ} \mathrm{C}$ during 12 hours in a hot air oven. The reduction was confirmed by TGA and FTIR. 3 wt.\% rGO was then dispersed in a silicone rubber matrix and homogenous dispersion was demonstrated by the scanning electron microscopy. The rGO-filled silicone rubber (120 and $180{ }^{\circ} \mathrm{C}$ reduced) exhibited a non-linear resistivity when exposed to an increasing electric (DC) field. The conductivity decreased from $10^{14}$ to $10^{11} \mathrm{Ohm} \mathrm{m}$ when the electric field increasing from 0.2 to $6 \mathrm{kV} / \mathrm{mm}$. The onset of the non-linear conduction occurred in the range of $1-2$ $\mathrm{kV} / \mathrm{mm}$. The long-term stability of the conductivity of the silicone rubber composite was tested. After 47 days ageing at $120{ }^{\circ} \mathrm{C}$, therGO/silicone rubber composite exhibited a slight increase in the onset of non-linear conduction, as well as a minor increase in resistivity.
\end{abstract}

\section{Introduction}

A general tendency has been that insulation systems in high voltage equipment become exposed to higher electric, thermal, mechanical and environmental stresses. Nanostructured polymeric materials provide a great number of opportunities in this context thanks to their high specific interfacial area; providing a molecular toolbox for obtaining excellent insulation materials [1-3]. For example polymer nanocomposites can be used for the development new types of resistive field grading materials for use in HVDC cable accessories, allowing more compact and reliable designs. By careful control of the particle size distribution, particle dispersion and inter-particle distance between semiconducting nanoparticles in a polymer matrix, the non-linear resistivity of the material can be controlled by varying the applied electric field [4, 5]. Resistive field grading materials can also be manufactured by adding thermally reduced graphene oxide to a polymer matrix [6]. Thanks to the high aspect ratio of the graphene oxide sheets, a percolated network structure can be obtained with very low filler content ( $<5 \mathrm{wt} \%)$. A major concern of this type of materials is however the long-term stability of the dielectric properties. In this paper the influence on the degree of reduction of graphene oxide, dispersed in a silicone rubber matrix, on the dielectric properties is discussed. The long-term stability of resistivity of the composite material is also investigated.

\section{Experimental}

Sylgard 184 silicone elastomer was supplied by Dow Corning Corporation. The freeze-dried graphene oxide (GO) was purchased from Abaloyx AS, Norway, in a form of brown "foam". The received GO was thermally reduced at 120 or 180 for 12 hours in a hot air oven before mixing into the silicone. $3 \mathrm{wt} . \%$ of the reduced graphene oxide (rGO) was firstly mixed with Sylgard 184A using a Flacktek Speed Mixer. The mixing speed is $3500 \mathrm{rpm}$ and the total mixing time is $30 \mathrm{~min}$ with a cooling in between each $2 \mathrm{~min}$. Then, Sylgard 184B and additional Pt catalyst were added to the mixture, followed by another 30s mixing at $3500 \mathrm{rpm}$. The mix ratio for Sylgard $184 \mathrm{~A}$ and B is 10:1. Finally, the mixture was poured in the mould and cured at $180^{\circ} \mathrm{C}$ for 30 min using a compression moulding machine. Films with a diameter of $30 \mathrm{~mm}$ and a thickness of 1 $\mathrm{mm}$ were prepared. All prepared samples were stored in a desiccator to avoid moisture ingress from the ambient environment. Infrared spectra were obtained by using a Perkin-Elmer Spectrum 2000 at $1 \mathrm{~cm}^{-1}$ intervals. Thermogravimetric analysis was carried out on a Mettler Toledo TGA/DSC 1 . The samples were heated from $25^{\circ} \mathrm{C}$ to $800{ }^{\circ} \mathrm{C}$ at a rate of $10^{\circ} \mathrm{C} \mathrm{min}{ }^{-1}$. The filler distribution in the composites is assessed by examining microtomed surfaces in a Hitachi S-4800 field emission scanning electron microscope (SEM). A guarded brass measuring electrode with diameter of $20 \mathrm{~mm}$ was used for DC resistivity measurements. The polarization process took place under constant DC electrical field for $12 \mathrm{~min}$, then following by a $12 \mathrm{~min}$ depolarization. The resistivity was calculated based on the polarization and depolarization current.

\section{Results and Discussion}

The electric field dependent resistivity of pure silicone and silicone composites between 0.2 and $6 \mathrm{kV} / \mathrm{mm}$ is summarized in Figure 1. The non-linear resistivity is in the same range as previously reported data of a silicone rubber filled with 3 wt.\% rGO [6]. When 3 wt.\% as received GO was added, the composite showed a high resistivity $\left(1.3 \times 10^{15} \mathrm{ohm} \mathrm{m}\right)$. It decreased slightly to 
$6.3 \times 10^{12} \mathrm{ohm} \mathrm{m}$ at $6 \mathrm{kV} / \mathrm{mm}$, which is still in the range of a filled silicone rubber material for electrical insulation. However, after adding 3 wt.\% graphene oxide, reduced at 120 or $180{ }^{\circ} \mathrm{C}$, a stronger non-linear resistive behavior of the composites was observed. The resistivity of both samples decreased around 4 orders of magnitude with increasing electric field. The onset of non-linearity started around $1 \mathrm{kV} / \mathrm{mm}$. Compared with the composite containing $\mathrm{GO}$ reduced at $120^{\circ} \mathrm{C}$, the one filled with $\mathrm{GO}$ reduced at $180{ }^{\circ} \mathrm{C}$ was more conductive at fields higher than $1 \mathrm{kV} / \mathrm{mm}$. One interesting phenomenon was that at lower field $(<1 \mathrm{kV} / \mathrm{mm})$ the resistivity of composites was higher than the pure silicone, which probably due to the electrons was trapped by the remaining carbonyl and carboxyl groups in composite at lower field. The pure silicone reference sample exhibited insulating properties within the tested electric field.

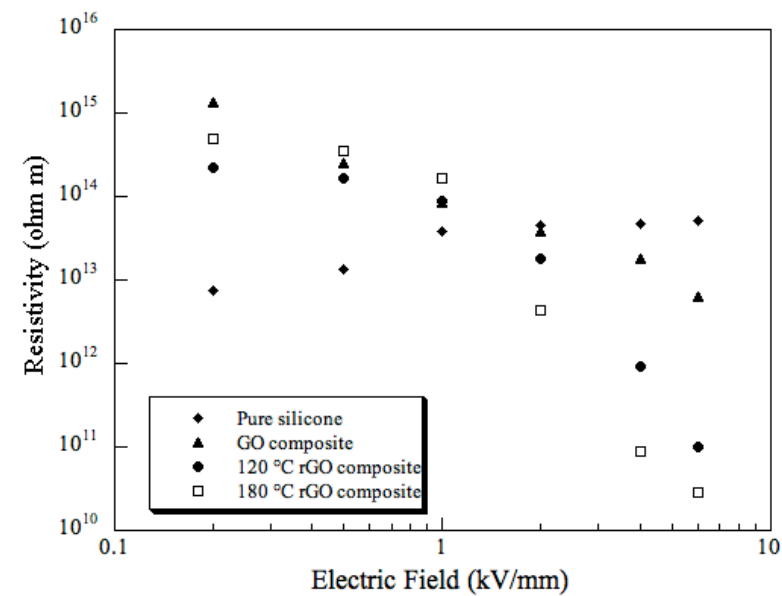

Figure 1. DC resistivity of pure silicone (diamonds) and silicone rubber filled with 3 wt.\% GO (triangles), $120^{\circ} \mathrm{C}$ rGO (circles), $180^{\circ} \mathrm{C} \mathrm{rGO}$ (squares).

In order to assess the effects of the thermal reduction of the GO, thermal gravimetric analysis (TGA) was performed in a nitrogen environment. The TGA curve of GO and rGO with different reduction temperature is shown in Figure 2. The GO showed three distinct mass loss steps. Below $100{ }^{\circ} \mathrm{C}$, around $9 \%$ mass loss can be attributed to the evaporation of the trapped water between GO sheets [7]. A rapid mass loss of $20 \%$ around $200{ }^{\circ} \mathrm{C}$ was due to the pyrolysis of oxygencontaining functional groups [8]. The gradual mass loss above $250{ }^{\circ} \mathrm{C}$ was the further removal of oxygen functional groups. Another rapid mass loss (around $50 \%$ ) starting from $500{ }^{\circ} \mathrm{C}$ can be attributed to the decomposition of GO carbon skeleton. The mass loss of GO reduced at $120^{\circ} \mathrm{C}$ and $180^{\circ} \mathrm{C}$ is less compared with GO suggesting that they had been partially reduced.

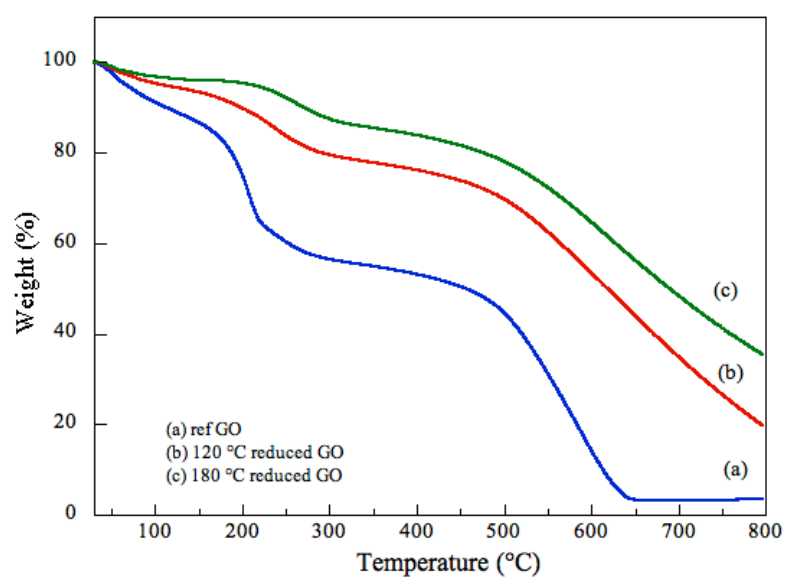

Figure 2. TGA analysis of GO and thermally reduced GO at 120 and $180^{\circ} \mathrm{C}$.

Figure 3 shows the IR spectra of GO and rGO. For the spectrum of GO, the absorption at $3323 \mathrm{~cm}^{-1}$ was attributed to stretching mode of $-\mathrm{OH}$ group in $\mathrm{H}_{2} \mathrm{O}$. This assignment can be correlated with corresponding $\delta$ $\left(\mathrm{H}_{2} \mathrm{O}\right)$ mode at $1623 \mathrm{~cm}^{-1}$. The peak at $1729 \mathrm{~cm}^{-1}$ was assigned to $\mathrm{C}=\mathrm{O}$ stretching vibrations from carbonyl and carboxyl groups. The peaks at 1368, 1227 and 1058 were attributed to $-\mathrm{COH}$ bending, $\delta(\mathrm{C}=\mathrm{C})$ mode and C-O functional groups, respectively $[9,10]$. After thermally reduction, these peaks decreased or disappeared as can be seen in Fig. 3b-c. For rGO spectrum, the $-\mathrm{OH}$ stretching mode from $\mathrm{H}_{2} \mathrm{O}$ disappeared and the $-\mathrm{OH}$ stretching vibration within rGO $\left(\approx 3433 \mathrm{~cm}^{-1}\right)$ decreased with increasing reduction temperature. The peak at $1623 \mathrm{~cm}^{-1}$ associated with water was also disappeared, which indicated the removal of intercalated $\mathrm{H}_{2} \mathrm{O}$ molecules. The intensity of $\mathrm{C}=\mathrm{O}$ stretching was quite stable. A new peak at 1582 $\mathrm{cm}^{-1}$ appeared for the rGO, which was assigned to $\mathrm{C}=\mathrm{C}$ stretching mode. The decreasing of $\mathrm{C}-\mathrm{O}$ functional group with increasing temperature was also observed.

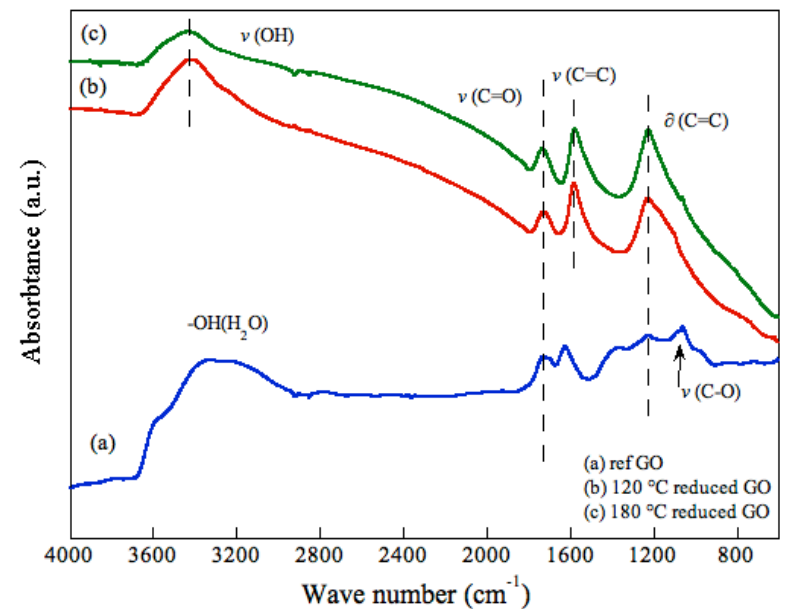

Figure 3. IR transmission spectra of GO and thermally reduced $\mathrm{GO}$ at 120 and $180^{\circ} \mathrm{C}$. 
Figure 4 displays the morphology of $120^{\circ} \mathrm{C}$ and 180 ${ }^{\circ} \mathrm{C}$ rGO composites. It can be seen that the rGO sheets were uniformly distributed over the cross section in the rubber matrix. The majority of the rGO was in the form of individual sheets, and only few multi layer structure were observed. Moreover no delamination between reduced graphene oxide and silicone matrix was observed. This suggested that the high shear mixing process provided enough force to separate rGO sheets.

The effect of thermal ageing of the silicone rubber composites filled with $120{ }^{\circ} \mathrm{C}$ rGO was also investigated. The samples were wrapped in protective alumina foil and put in a hot air oven at $120{ }^{\circ} \mathrm{C}$ during 47 days. The resistivity as function of electric field was measured at $23^{\circ} \mathrm{C}$, as shown in Figure 5 . The results showed an increase of resistivity with ageing for both pure silicone rubber and the rubber containing $120{ }^{\circ} \mathrm{C}$ rGO. The pure silicone showed insulating properties all the time, whereas the electric field dependent resistivity of the composite was still observed after ageing.

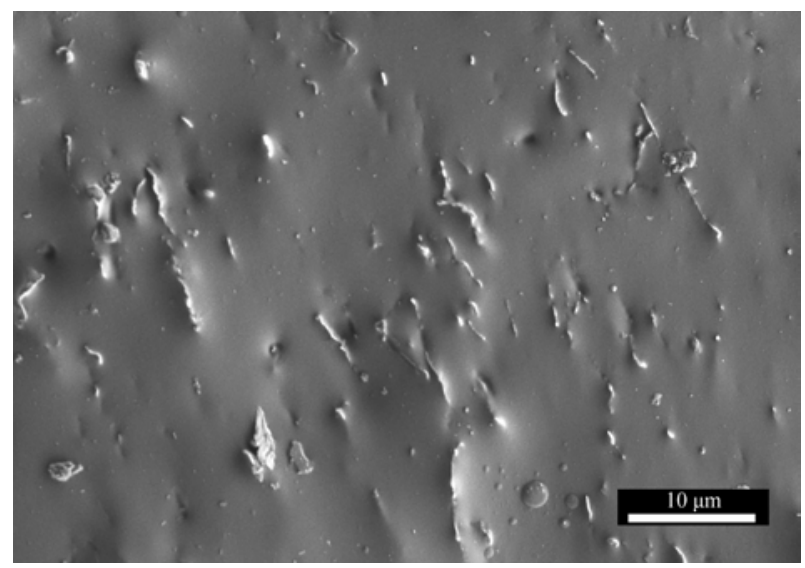

(a)

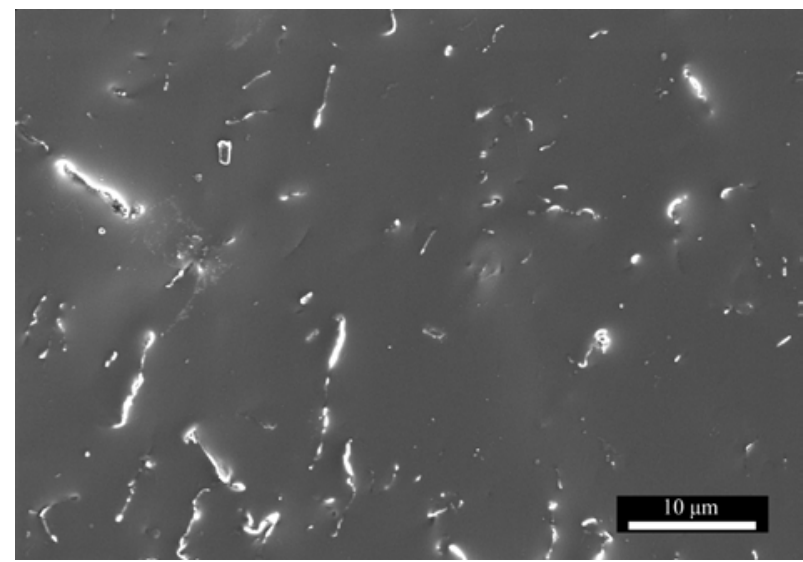

(b)

Figure 4. Scanning electron micrographs of microtomed rGO composites contained with (a) $120{ }^{\circ} \mathrm{C}$ rGO and (b) $180{ }^{\circ} \mathrm{C}$ rGO.

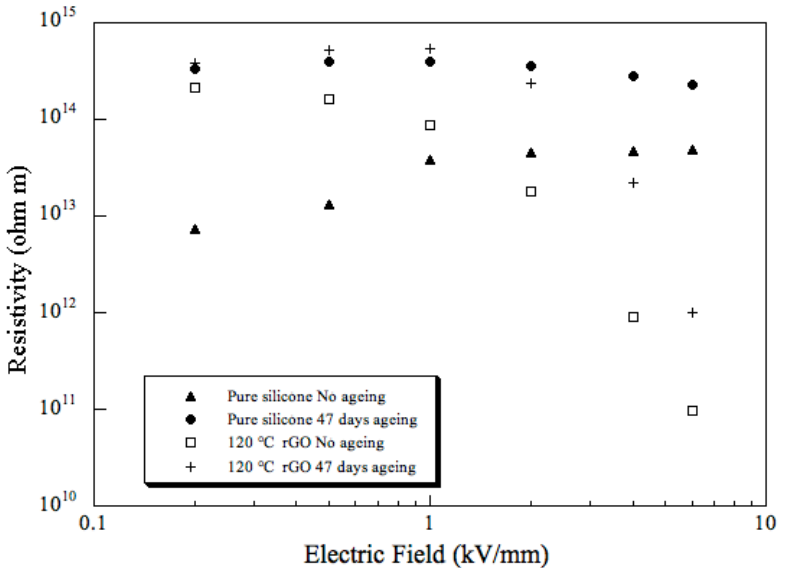

Figure 5. Resistivity of pure silicone and rGO filled composite as function of electric field at $23{ }^{\circ} \mathrm{C}$.

Based on the increased conductivity of thermally reduced GO sheets it would be expected that the conductivity of the rGO composite would increase further after thermal ageing. This indicate that the nonlinear behavior of the composite material is not only influenced by the degree of oxidation of the GO, but also the contact points between the GO sheets in the polymer matrix. This requires further investigations.

\section{Conclusions}

Graphene oxide was thermally reduced at 120 and 180 ${ }^{\circ} \mathrm{C}$ during 12 hours in a hot air oven. The reduction was confirmed by TGA and FTIR. 3 wt.\% rGO was then dispersed in a silicone rubber matrix and homogenous dispersion was demonstrated by the scanning electron microscopy. The electrical resistivity of the composites was investigated. The rGO-filled silicone rubber (120 and $180{ }^{\circ} \mathrm{C}$ reduced) exhibited non-linear resistivity when exposed to an increasing electric (DC) field, which decreasing from $10^{14}$ to $10^{11} \mathrm{Ohm} \mathrm{m}$ when the electric field is increasing from 0.2 to $6 \mathrm{kV} / \mathrm{mm}$. The onset of the non-linear conduction occurred in the range of $1-2 \mathrm{kV} / \mathrm{mm}$. After 47 days ageing at $120{ }^{\circ} \mathrm{C}$, a rGO/silicone rubber composite exhibited a slight increase in the onset of non-linear conduction, as well as a minor increase in resistivity

\section{Acknowledgements}

EIT KIC InnoEnergy, SweGRIDS, Swedish Foundation for Strategic Research (SM14-0034; H. Hillborg) and $\mathrm{ABB} A B$ are thanked for their financial support. 


\section{References}

[1] T. L. Hanley, R. P. Burford, R. J. Fleming and K. W. Barber "A general review of polymeric insulation for use in HVDC cables”, IEEE Electr. Insul. Mag., 2003, pp. 13-24.

[2] L. Donzel, T. Christen, R. Kessler and H. Gramespacher, "Silicone composites for $\mathrm{HV}$ applications based on microvaristors”, Int. Conf. Solid Dielectr., Toulouse, France, 2004, pp. 403406.

[3] T. Christen, L. Donzel, and F. Greuter, "Nonlinear resistive electric field grading Part 1: Theory and simulation”, IEEE Electr. Insul. Mag., 2010, pp. 48-60.

[4] L.S. Schadler, X. Wang, J. K. Nelson and H. Hillborg, "Dielectric polymer nanocomposites", Springer US, 2010, pp. 259-284.

[5] X. Wang, J. K. Nelson, L. S. Schadler and H. Hillborg, "Mechanisms leading to nonlinear electrical response of a nano $\mathrm{p}$-SiC/silicone rubber composite", IEEE Trans. on Dielectr. Electr. Insul., 2010, pp. 1687-1696.

[6] Z. Wang, J. K. Nelson, H. Hillborg, S. Zhao and L. S. Schadler, "Graphene oxide filled nanocomposite with novel electrical and dielectric properties", Adv. Mater., 2012, pp. 3134-3137.

[7] S. Dubin, S. Gilje, K. Wang, V. C. Tung, K. Cha, A. S. Hall, J. Farrar, R. Varshneya, Y. Yang and R. B. Kaner, “A one-step, solvothermal reduction method for producing reduced graphene oxide dispersions in organic solvents”, ACS Nano, vol. 4, 2010, pp. 3845-3852.

[8] P. Song, X. Y. Zhang, M. X. Sun, X. L. Cui and Y. H. Lin, "Synthesis of graphene nanosheets via oxalic acid-induced chemical reduction of exfoliated graphite oxide” RSC Adv., vol. 2, 2012, pp. 1168-1173.

[9] S. Yang, W. Yue, D. Huang, C. Chen, H. Lin and $\mathrm{X}$. Yang, “A facile green strategy for rapid reduction of graphene oxide by metallic zinc", RSC Adv., vol 2, 2012, pp. 8827-8832.

[10] T. Szabo, O. Berkesi, P. Forgo, K. Josepovits, Y. Sanakis, D. Petridis and I. Dekany, "Evolution of surface functional groups in a series of progressively oxidized graphite oxides”, Chem. Mater., 2006, pp. 2740-2749. 